

\section{Las emociones del cuerpo con especial referencia a la psicosis. Lectura de una experiencia con mirada antropológica ${ }^{1}$}

The emotions of the body with special reference to psychosis. Reading an experience with an anthropological perspective // As emoções do corpo com referência especial à psicose. Lendo uma experiência com uma perspectiva antropológica

Rosaura Yépez Vásquez ${ }^{2}$

Universidad Autónoma del Estado de México, México

rosaurayev@outlook.com

Revista Corpo-grafías: Estudios críticos de y desde los cuerpos / Volumen 7 - Número 7 / Enero - diciembre 2020 / ISSN impreso 2390-0288, ISSN digital 2590-9398 / Bogotá, D.C., Colombia / 221-237

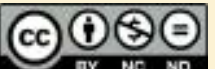

Fecha de recepción: 17 de enero de 2019

Fecha de aceptación: 2 de mayo de 2019

DOI: https://doi.org/ 10.14483/25909398.15520

Cómo citar este artículo: Yépez Vásquez, R. (2020, enero-diciembre). Las emociones del cuerpo con especial referencia a la psicosis. Lectura de una experiencia con mirada antropológica. Revista Corpo-grafías: Estudios críticos de y desde los cuerpos, 7(7), pp. 221-237 / ISSN 2390-0288.

\footnotetext{
$1 \quad$ Articulo de reflexión Investigación: El presente artículo surge de mi proyecto de investigación: "Bioquímica de los alimentos y su relación con la salud biopsicoemocional del cuerpo en el Ser Humano", que está en desarrollo desde junio de 2008. Proyecto del cual, presentaré una conferencia en el I Congreso Internacional Académico Interdisciplinario de Historiadores de Ciencias de la Salud, que será del 21 al 25 de octubre del año en curso, en la Facultad de Medicina de la Universidad Autónoma del Estado de México, Toluca, en colaboración con la Escuela de Medicina de Campus Universitario Siglo XXI y Red Mexicana de Historiadores de Ciencias de la Salud.

2 Profesora e investigadora de la Facultad de Antropología, Universidad Autónoma del Estado de México. Doctora en Antropología por la UNAM.
} 


\section{Resumen}

Este estudio es resultado de una lectura experiencial con adolescentes que han vivido episodios de depresión, ansiedad y en particular de psicosis, teniendo como objetivo de discusión el ser humano como unidad bio-psico-social. En tal sentido se formula el problema a investigar: ¿Qué factores originaron las alteraciones psicoemocionales en los adolescentes de este estudio, y qué métodos se utilizaron en el tratamiento psiquiátrico y psicoterapéutico?, ¿Por qué ciertas alteraciones psicoemocionales en adolescentes son diagnosticadas como psicosis de carácter biológico, siendo que pueden ser de presencia exógena? Se revisan algunos métodos curativos desde el enfoque psiquiátrico de Carl Jung, el método psicoterapéutico simbólico de Sechehaye, un método cristiano de sanación, en pacientes diagnosticados psiquiátricamente con "esquizofrenia". Finalmente, se narra y explica la historia particular de un adolescente diagnosticado con esquizofrenia /fobia social y su tratamiento. Se finaliza parcialmente este estudio con una perspectiva antropológica.

\section{Palabras clave}

Cuerpo; ser humano; psique; emociones; psicosis; curación-sanación

\section{Abstract}

This study is the result of an experiential reading with adolescents who have experienced episodes of depression, anxiety and in particular of psychosis, having as objective of discussion the Human Being as a bio-psycho-social unit. In this sense the problem is formulated to investigate: What factors originated the psycho-emotional alterations in the adolescents of this study, and what methods were used in the psychiatric and psychotherapeutic treatment?, Why certain psycho-emotional alterations in adolescents are diagnosed as psychosis of biological character, being that they can be of exogenous presence? Some curative methods are reviewed from the psychiatric approach of Carl Jung, the symbolic psy- chotherapeutic method of Sechehaye, as well as a Christian method of healing, in patients diagnosed psychiatrically with "schizophrenia". Finally, the particular story of a teenager diagnosed with schizophrenia / social phobia and its treatment is narrated and explained. This study is partially completed with an anthropological perspective.

\section{Keywords}

Body; human being; psyche; emotions; psychosis; healing-healing

\section{Resumo}

Este estudo é o resultado de uma aula experimental com adolescentes que viveu episódios de depresión, ansiedad e em particular de psicosis, teniendo como tema de discusão ao Ser Humano como uma unidade bio-psico-social. En el factor se formula el problem a investigar: ¿Qué factors originaron as alteraciones psicoemocionales en los adolescentes de estudio, y qué methods seotel on the tratamiento psiquiátrico y psicoterapéutico ?, ¿Por qué ciertas alteraciones psicoemocionales en adolescentes son diagnosticadas como psicosis de exemplo biológico, siendo que pueden ser de presencia exógena? Se revisan algunos methods curative from the enfoque psiquiátrico de Carl Jung, o método psicoterapêutico simbólico de Sechehaye, como um método cristão de sanação, em pacientes diagnosticados psiquiátricamente com "esquizofrenia". Finalmente narra y explica a história particular de um adolescente diagnosticado com esquizofrenia / fobia social y su tratamiento. Se finaliza este processo com uma perspectiva antropológica.

\section{Palavras-chave}

Corpo; ser humano; psique; emoções; psicose; cura-cura

\section{Introducción}

La psiquiatría, el arte de curar el alma, todavía se encuentra en la puerta, tratando en vano de pesar y medir, como ocurre en los demás departamentos científicos. Hace mucho que sabemos que se trata de un órgano 
definido, el cerebro; pero solo más allá del cerebro, más allá del sustrato anatómico nos encontramos con lo que para nosotros es importante: la psiquis, tan indefinible como siempre, todavía eludiendo toda explicación por ingeniosa que sea...El dogma materialista, como lo formula la psiquiatría, dice: "Enfermedades mentales son enfermedades del cerebro" (Jung, 2015, pp. 11, 67).

La etnopsicología y la etnopsiquiatría surgen como alternativas para la comprensión de la enfermedad mental en culturas distintas a las occidentales. Ambas buscan nuevas explicaciones a la observación de distintos comportamientos en la enorme diversidad de culturas, cosmovisiones y maneras de ver y entender al mundo. Al contar y considerar a la cultura como un factor fundamental para entender cierta conducta en un individuo, se abren nuevos horizontes para su explicación - comprensión (Florence Rosemberg, 2008, p. 72).

Vivimos con el cuerpo-mente-emociones, somos un cuerpo, vivimos en él y a partir del mismo trascendemos. De repente en el transitar de nuestras vidas, el tiempo y el espacio giran y brindan repositorios profundos de reflexión, el cuerpo es capaz de sentir y exaltar que ya "no hay experiencia más concreta que la del cuerpo, vivimos el mundo desde él y cotidianamente experimentamos a través de él un sin fin de sensaciones: placer, hambre, dolor" (Aguilar y Soto, 2013, p. 5), sentires, alegrías, esperanzas, motivaciones, pero en esas sensaciones corporales también despiertan creencias y alineamientos afectivos, que nos llevan a comprender y actuar como sujeto de acción, con la única convicción que lo que más importa, es esa acción humana para escuchar, extender un abrazo, sonreír y llorar ¿por qué no?, aunar tu propio cuerpo, al dolor de aquel otro cuerpo frágil, confundi do, escondido en el recóndito de su "inconsciente", ${ }^{3}$ "...

$3 \quad$ Para Jung, la topografía básica del inconsciente la describe como si fuesen dos esferas de operación relacionadas entre sí. La esfera o capa superior es el inconsciente personal, es el estrato inmediatamente inferior de la conciencia, es el más superficial y la en tanto cuerpos en-carnados, toda reflexión humana, y toda escritura que intente plasmarla, se origina en experiencias sensorio-afectivo-cognitivas de cuerpos enel-mundo", no obstante "siempre es un desafío intentar develar cómo operan estos lazos en reflexiones y escrituras concretas" (Citro, 2011, p. 17).

Hablar del cuerpo implica referirnos al hombre, por ende, al ser humano con sus corporeidades en sus distintos contextos donde transitan sus actividades cotidianas. En tal sentido, ¿Qué es el ser humano? Torralba (2008, p. 23) expresará: "No cabe duda de que una de las cuestiones más arduas, desde el punto de vista filosófico, consiste en caracterizar esencialmente al ser humano y sus diversas dimensiones, el cual puede ser definido de maneras muy diferentes". De acuerdo con este autor, en tanto que realidad personal, el ser humano es un sujeto de derechos llamado a construir un itinerario libre con su vida en un marco social y cultural determinado. Por tanto, alude Torralba, en términos generales la experiencia de la enfermedad, del sufrimiento o de la vulnerabilidad no es ajena a la vivencia humana, sino muy propia, y afecta de una manera decisiva a su itinerario y sus horizontes de referencia.

Actualmente, transitamos en una sociedad acelerada de altas tecnologías en los diferentes campos científicos y de alto consumo en esta sociedad contemporánea. Se han creado millones de necesidades para consumir y el hombre se ha instalado en objeto y sujeto de consumo. Se le impone subliminalmente con el consumo, un estilo

zona más fácilmente accesible del inconsciente. Debajo de este inconsciente personal, está el inconsciente colectivo, o mente racial, cuyas hondas profundidades constituyen un desafío a toda descripción (Winski, 1973, p. 55). La psique para Jung, es "la totalidad de la mente" y se regenera a sí misma, tiende a la integración y señala al individuo la actualización de sí mismo cuando se le desvía -la libido junguiana es "la energía psíquica" que se manifiesta en forma de voluntad inexorable hacia la totalidad, proceso que Jung llama "individuación" (Winski, Entendiendo a Jung, 1973, pp. 25-26). 
de vida que crea identidad y estatus, presionado así, a mantenerse en este nuevo orden social. Los jóvenes sobretodo, enfrentan un gran desafío en esta sociedad posmoderna. ${ }^{4}$

Enfrentamos una sociedad y cultura del abandono, de la indiferencia, del egoísmo, del maltrato psicológico en los diferentes contextos socio culturales, como en los escolares tan actuales, entre otros. Por ello, habrá que repensar antropológicamente nuestro cuerpo-mente-emociones en el contexto fundamental de la familia, cimiento de la autorreflexión, de los valores éticos humanos, de tal manera que los jóvenes estén capacitados para enfrentar los retos de esta sociedad del siglo XXI. Brian Turner (1994, p. 29) ha manifestado que la «crisis» en las enfermedades nerviosas de finales del siglo XIX produjo un grupo de condiciones -anorexia, agorafobia, histeria anoréxica, enfermedad de vírgenes, o varias enfermedades de desgaste- que se pueden interpretar

$4 \quad$ Las prácticas y las formas del saber han tomado nuevos rumbos en la historia reciente. A partir de la Segunda Guerra Mundial, cuando se instauran categóricamente las nuevas tecnologías, la sociedad y la cultura contemporáneas entran en una crisis que se manifiesta en todos los sentidos e implica un paquete considerable de cambios en las estructuras de la tradición de la modernidad. La condición posmoderna de Jean François Lyotard, es un informe sobre estas transformaciones operadas en el presente, en particular sobre la condición del saber en las sociedades más desarrolladas, las posindustriales. A esta nueva condición del saber se la ha designado con el término "posmoderna" [...] El saber no se reduce al saber científico. De hecho, la ciencia compite con la otra gran forma del saber, el narrativo, que no ha encontrado en la cultura occidental la misma legitimidad [...] En la posmodernidad, no obstante, a la hegemonía del poder de la ciencia, que se encuentra en estado de deslegitimidad y que tiene un saber parcial, se opone el saber narrativo. Si la ciencia está hecha de enunciados denotativos, el saber se entiende como un conjunto más amplio que comprende el saber-hacer, el saber-vivir, el saber-oír, entre otros, y todos los tipos de enunciación: denotativos, "performativos", prescriptivos (Lyotard, 2004, pp. 25-28): los juegos de lenguaje, de los que habla Wittgenstein, que hacen posible el lazo social. La naturaleza de este lazo es una en la modernidad y otra, por supuesto, en la posmodernidad (Espinoza, 2010, pp. 11-13). como una sintomatología de cambios en la relación de sexos, entre los espacios público y privado, entre la familia y la economía en el contexto de la medicina creciente sobre las cuestiones morales.

Al respecto, ¿Se puede hablar de un cambio en la psico(pato)logía del sujeto neoliberal y posmoderno que sea al menos algo diferente a la del periodo capitalista anterior tan cercano al tiempo? (Guinsberg, 2010, pp. 26-27), incuestionablemente sí, porque se trata de un modelo que no ha cambiado en lo central, pero ha tomado formas marcadamente diferentes y radicales como para significar una modificación lo suficiente importante que no se reduce a lo económico, sino también pretende abarcar todos los aspectos sociales y políticos (Guinsberg, 2010).

De esta forma, frente a estos desafíos ¿qué hay que hacer dentro de nuestra disciplina antropológica?, Ramírez (2010, p. 15) propone, que una de las tareas consiste en contribuir a la preparación de antropólogos físicos situados con la realidad del mundo contemporáneo; en el sentido de consolidar un pensamiento hacia una antropología física crítica, que surja desde una visión epistemológica, ontológica y dialéctica del cuerpo como experiencia y agencia; y a la cultura como productora de salud, como determinante de la enfermedad y como modeladora de la experiencia. Lo propuesto por Ramírez, lleva a considerar que tal como la sociedad y la cultura informan a través de los medios de comunicación de una diversidad de alternativas para conservar un alto grado de salud, también promueve la ingesta de una diversidad de biotecnologías en el consumo de alimentos procesados y ultraprocesados, lo cual ha llevado a modificar los hábitos alimentarios no solo en la estructura familiar, sino en los diferentes sistemas tradicionales de preparar los alimentos en casa. Todos estos grandes cambios, han promovido cambios en las condiciones de salud y enfermedad.

En cuanto a los modelos de la enfermedad, Boixereu $(2008$, p. 227) resalta que la enfermedad se representa 
y es representada como un fenómeno pluridimensional de diversos significados, constituyen la explicación-interpretación de las realidades y se elaboran para conocer una de ellas en concreto. La percepción subjetiva de la persona sobre su enfermedad no es la misma que la de un observador, sea este un profesional de la salud, un familiar o perteneciente al entorno social. Por ejemplo, la antropología de la medicina enfatiza la consideración de las relaciones entre medicina y cultura, es decir, entre los factores biológicos y todo lo demás, mientras que en la antropología de la salud se parte de las personas y, desde ellas, se abre el abanico de interacciones recíprocas y con el entorno.

\section{Metodología}

En esta presentación no se discutirán los enfoques teóricos de las emociones del cuerpo desde las diferentes disciplinas científicas, principalmente dentro del amplio trabajo teórico etnográfico que la antropología ha realizado en el campo de sus actividades, principalmente de la "Antropología médica. Teorías sobre la cultura, el poder y la enfermedad" (Martínez, 2011), "del psicoanálisis a la etnopsiquiatría, la etnopsiquiatría crítica" (Morales, 2016), "Antropología médica e interculturalidad" (2016) de Roberto Campos Navarro, entre otras diversas obras. Significa mucho en este primer caminar corporal y emocional, voltear la mirada al tratamiento psicoterapéutico realizado con pacientes que fueron diagnosticados "con esquizofrenia" ${ }^{5}$ dejando de lado el aspecto psicológico de la situación psicoemocional. Estos mismos pacientes de inmediato fueron atendidos por un reconocido doctor en medicina psiquiátrica, quien descartó esquizofre-

5 La esquizofrenia es un tipo de psicosis. El término esquizofrenia se emplea para referirse a aquellas enfermedades psicóticas en que los cambios de conducta o los síntomas persisten durante un periodo no inferior a los seis meses. Tanto los síntomas como la duración de la enfermedad varían según el caso, y al contrario de lo que se suele creer, muchas personas afectadas de esquizofrenia llevan una vida plena y feliz, logrando muchas de ellas una total recuperación (Department of Human Services, State Government Victoria. www.eppic.org.au). nia. Después de dos citas exhaustivas, el diagnóstico fue "fobia social"6 o algún tipo de depresión. Sin embargo, en este trabajo intenta argüir acerca de la psicosis, para después centrar la discusión del tratamiento de los jóvenes adolescentes en mención.

El cuestionamiento en este ensayo inicial de investigación sobre las emociones del cuerpo con particular referencia a la psicosis plantea en primer lugar: ¿Qué factores desencadenaron las alteraciones psicoemocionales en los adolescentes de este estudio, y qué métodos se utilizaron en el tratamiento psiquiátrico y psicoterapéutico?, ¿Por qué ciertas alteraciones psicoemocionales en adolescentes son diagnosticadas como psicosis de carácter biológico, siendo que pueden ser de presencia exógena?

Indagar sobre la psique, su operatividad y funciones estructurales, procesos, sistemas o pautas dinámicas, inclusive su trascendencia, implica interrogarse qué hay más allá de solo un cuerpo biológico. Otras interrogantes que surgen en este estudio son ¿Cuál es la esencia y la estructura de la psique en relación con las alteraciones psicoemocionales del cuerpo?, ¿Qué relación hay entre la conciencia y el inconsciente en episodio de psicosis o de tipo de alteración emocional?, ¿Dónde está localizada la psicogénesis de las emociones del cuerpo? Preguntas que, por razones de espacio, se resolverán posteriormente en una siguiente publicación. Estas interrogantes facilitan visualizar cuán profundo es el estudio de la psique y las emociones en el ser humano. De ahí su gran complejidad bio-psico-afectivo-sensorial, como familiar, social

6 La fobia social, también llamada ansiedad social o estrés social. "La ansiedad y fobia social están determinadas por diversos aspectos de actuación e interacción en las situaciones sociales, cobrando importancia los componentes de temor y evitación informados por los sujetos fóbicos. Distintos factores evolucionistas, familiares, ambientales, evolutivos, temperamentales, neurobiológicos (genéticos, biológicos y neuroendocrinos), psicológicos y socioculturales se asocian a este trastorno, reflejando la gran complejidad del mismo" (Sierra, 2006, p. 473). 
y cultural. El ser humano es un ser de sentimientos, de afectos y de una gran necesidad de comprensión, quizás no de interrogación cuando está pasando por episodios de vulnerabilidad emocional.

Estimo que desde la antropología como ciencia que estudia la evolución del hombre, la sociedad y su cultura, se desarrollaran nuevas alternativas metodológicas desde la antropología médica, en especial la etnopsiquiatría y etnopsicología en el problema de las alteraciones psicoemocionales considerando el contexto familiar, social y cultural, como texto de información e interpretación socio familiar. Continuar investigando desde una antropología de la psiquiatría y psicología con enfoques analíticos simbólicos, como con terapias conductuales y de contexto, permitirá establecer un equilibrio homeostático entre lo biológico, lo social-cultural y fundamentalmente en el entorno de la vida familiar, base fundamental de la estabilidad, la paz, la armonía y la afectividad de la familia.

\section{El inconsciente y su importancia en las alte- raciones de la mente}

Es un gran desafío, un reto intentar descifrar cómo operan esos cambios afectivos en la psique humana. Jung (2015, pp. 58-65) en su apartado sobre "la importancia del inconsciente en psicopatología", refiere que desde el punto de vista del funcionamiento del cerebro, puede ser inconsciente de dos maneras: fisiológica y psicológicamente, que para este trabajo, solo se aborda el segundo. Define al inconsciente, como la suma de todos los hechos psíquicos que no se perciben y son, por lo tanto, inconscientes. Estos hechos no poseen intensidad suficiente para cruzar el umbral que separa a la conciencia del inconsciente. En efecto, permanecen debajo de la superficie de la conciencia y se manifiestan, algunas veces, en forma subliminal. Al respecto Jung (2015) formula la pregunta sobre la importancia del inconsciente para la psicopatología: ¿De qué manera podemos esperar que se comporte el material psíquico inconsciente en los casos de psicosis y neurosis? Refiere que en las personas saludables la principal función del inconsciente consiste en efectuar una compensación y producir un equilibrio. Todas las tendencias conscientes extremas son mitigadas por un contra impulso en el inconsciente. En cuanto al análisis de los trastornos del equilibrio mental, sostiene que se ha reconocido, cuál es la importancia del inconsciente para la psicopatología. Para ello, plantea otra interrogante ¿dónde y cómo se manifiesta el inconsciente en condiciones mentales anormales?, sobre esta, sostiene que la forma en que trabaja el inconsciente se puede observar con toda claridad en trastornos de naturaleza psicogenética como la histeria, la neurosis obsesiva, entre otros. También refiere que desde hace tiempo se sabe que ciertos síntomas de esos trastornos son producidos por acontecimientos psíquicos inconscientes. También opina lo siguiente: "así como las ideas intuitivas de las personas normales no surgen de combinaciones lógicas de la mente consciente, las alucinaciones y las manías de los dementes no se origina a partir de procesos conscientes, sino inconscientes".

Carl Jung explica, que los pueblos primitivos pueden tener visiones y escuchar voces sin que estos perturben sus procesos mentales. Las alucinaciones muestran claramente, cómo una parte del contenido del inconsciente puede atravesar el umbral de la conciencia. Lo mismo vale para una idea fija, cuya aparición es extraña y al mismo tiempo inesperada para el paciente. Por lo que, la expresión "equilibrio mental" no es una mera metáfora, realmente se trata de un trastorno del equilibrio que existe entre los contenidos conscientes e inconscientes. Lo que ocurre, es que el funcionamiento normal del proceso del inconsciente se introduce de manera anormal en la mente consciente, perturbando así, la adaptación del individuo a su medio ambiente.

Se puede extraer de estas exposiciones de Car Jung, que nuestro cuerpo posee un recóndito mundo subjetivo llamado «inconsciente», y que este permanece en equilibrio 
homeostático con el mundo consciente (conciencia), y cuando nuestra esfera consciente entra en desajustes de sus vivencias y experiencias en el contexto de su existencia cotidiana, al parecer el inconsciente busca mantener ese equilibrio, e invade de manera anormal la conciencia, por tanto creará una inadaptabilidad de la persona, o bien digamos un nuevo proceso de adaptación a esta situación de alteración del equilibrio psíquico. En tal sentido se puede plantear ¿Cómo se introduce el dolor en el mundo subjetivo del cuerpo frente a las alteraciones de la psique?, ¿cómo influyen las vivencias y experiencias del dolor del cuerpo-mente-emociones?

Para reflexionar con mayor precisión acerca de la psique, Jung $(2004$, p.10) ha propuesto teóricamente, que hay un estrato superficial del inconsciente, que es, sin ninguna duda, personal, y se llama inconsciente personal. Este estrato descansa sobre otro más profundo que no se origina en la experiencia, no es una adquisición personal, sino que es innato: inconsciente colectivo, y Jung lo llama "colectivo» porque este inconsciente no es de naturaleza individual sino universal, es decir, que en contraste con la psique individual tiene contenidos y modos de comportamiento que son, "cum grano salis", los mismos en todas partes y en todos los individuos.

Es decir, es idéntico a sí mismo en todos los hombres y constituye un fundamento anímico de naturaleza suprapersonal que existe en cada uno. La existencia anímica solo se reconoce por la presencia de contenidos concienciables, por lo que, solo cabe hablar de un inconsciente cuando es posible mostrar la existencia de sus contenidos. Los contenidos del inconsciente personal, son los llamados complejos, que constituyen la intimidad de la vida anímica. $Y$ a los contenidos del inconsciente colectivo, los denomina "arquetipos", para el propósito de Jung, es útil y preciso, pues indica que los contenidos del inconsciente colectivo, son tipos

$7 \quad$ La expresión "arquetipo" procede de San Agustín y se trata de una paráfrasis explicativa del eidos platónico (Jung, 2004, p. 10). arcaicos o-mejor aún- primigenios, es decir imágenes universales acuñadas desde hace mucho tiempo. Al respecto nos dice, que puede aplicarse también, a los contenidos del inconsciente, la expresión "representaciones collectives", que Lévy-Bruhl (citado por Jung) usó para designar las figuras simbólicas de la cosmovisión primitiva, pues en principio se refiere casi a lo mismo.

Jung, brinda una referencia relevante del "inconsciente colectivo" cuando manifiesta que, en la doctrinas primitivas aparecen los arquetipos en una disposición especial, pero aquí, ya no son contenidos del inconsciente, sino que se han transformado en fórmulas conscientes, transmitidas por la tradición generalmente en forma de doctrina secreta, que es una expresión típica de la transmisión de contenidos colectivos que emergen originalmente del inconsciente. Los arquetipos también encuentran expresión en el mito y la leyenda.

Así, Carl Jung (2008, p. 21) en su libro El hombre y sus símbolos hace referencia, que hay innumerables cosas, más allá, del alcance del entendimiento humano. Usamos constantemente símbolos para representar conceptos que no podemos definir o comprender del todo. Esta, es una de las razones por las cuales todas las religiones emplean lenguaje simbólico o imágenes. Pero esta utilización consciente de los símbolos es solo un aspecto de un hecho psicológico de gran importancia: el hombre también produce símbolos inconsciente y espontáneamente en forma de sueños.

No es fácil captar este punto central, por ello Carl Jung (2008) nos dirá, hay que captarlo si queremos saber más acerca de las formas en que trabaja la mente humana. El hombre, si nos damos cuenta y reflexionamos un momento, jamás percibe cosa alguna por entero o la comprende completamente, puede ver, oír, tocar, gritar y puede utilizar los instrumentos más sofisticados para ver o escuchar sonidos (pienso si estuviera observando con un instrumento ultra sofisticado el cerebro humano 
para ubicar la psique), pero no podrá pasar el límite de la certeza, más allá de la cual no puede pasar el conocimiento consciente. Sobre esta reflexión, Jung expone lo siguiente:

Además, hay aspectos inconscientes de nuestra percepción de la realidad. El primero es el hecho de que, aun cuando nuestros sentidos reaccionan ante fenómenos reales, visuales y sonoros, son trasladados en cierto modo desde el reino de la realidad al de la mente. Dentro de la mente, se convierten en sucesos psíquicos cuya naturaleza última no puede conocerse, porque la psique no puede conocer su propia sustancia psíquica. Por tanto, cada experiencia contiene un número ilimitado de factores desconocidos, por no mencionar el hecho de cada objeto concreto es siempre desconocido en ciertos aspectos, porque no podemos conocer la naturaleza última de la propia materia.

Lo planteado hasta este momento, proclama comprender e indagar desde las emociones del cuerpo la configuración de nuestra psique (mente o alma). Norman Winski (1973, pp. 87-88) describe según Jung, las cuatro funciones de la psique humana: pensamiento, emoción, sensación e intuición. Estas, también constituyen las cuatro avenidas principales del saber y del relacionarse con la realidad, además se interrelacionan de manera frecuente y activan unas a otras. Entiendo entonces, que, ante un proceso de alteración del equilibrio de la psique, todo médico psiquiatra y psicoterapeuta, deberá trabajar con estas funciones de la psique, ofreciendo alternativas terapéuticas inter y transdisciplinarias para solucionar de manera adecuada y eficiente, el restablecimiento de la salud psíquica de la persona que enfrenta una situación de conflicto con su estado de salud mental. Además, se hace énfasis, un trabajo en equipo con la familia.

Ahora bien, ¿los procesos psíquicos están interconectados con el cerebro? Cuando hay alteraciones de la mente en sentido patológico definitivamente, hay una conexión. Cuando el cerebro permanece intacto sin ningún daño neuronal, está saludable a la vista de una resonancia magnética; entonces ¿dónde está la psique en las alteraciones psicoemocionales en la vida de ese ser humano con pensamientos, sentimientos, emociones, sensibilidades e intuiciones? ${ }^{8}$

¿Con qué elementos psíquicos se tiene que trabajar en la persona que enfrenta cambios de percepción en relación con la realidad de su cuerpo subjetivo (inconsciente) y cuerpo concreto-objetivo (conciencia), bajo su contexto familiar, social y cultural? De acuerdo a lo expuesto antes, se tendría que trabajar a nivel consciente e inconsciente. ¿Cuál de las funciones de la psique, intervienen de manera primaria en las alteraciones de la mente? El pensamiento es uno de las funciones primordiales para generar reacciones emocionales importantes en el cuerpo, como también la sensación y la intuición.

\section{Psicosis y neurosis}

Torres Ruiz (2003) médico psiquiatra refiere que el término psiquiatría (Hohann Cristian Heinroth) aparece para conceptualizar el area del conocimiento de las enfermedades mentales, persistiendo aún la discussion y el disenso, de sí la psiquiatría se encarga de los trastornos de los nervios (soma) de acuerdo al criterio de Cullen (1769), o de los trastornos del alma (psyche) según el pensamiento de Reil (1803).

Por lo que, esta polémica se origina cuando se plantea. "No todos los defectos del sistema nervioso son necesariamente acompañados por un trastorno mental", o "todo trastorno mental implica la existencia de una enfermedad del sistema nervioso" (Pichote, 1983). Así, en esta discussion aparece el término y concepto de psicosis (propuesto por Ernest Feuchtersleben, 1845).

8 Aquí inicia la discusión de toda la historia por comprender al hombre, quien es un cuerpo, un alma y un espíritu. Ya desde los antiguos filósofos griegos presocráticos como socráticos (Sócrates, Platón, Aristóteles) plantearon la discusión sobre el cuerpo y el «alma» como ente trascendente, más allá del cuerpo biológico. 
¿Qué es la neurosis? Se definía como un trastorno mental donde la alteración predominante consiste en un grupo de síntomas que es perturbador, inaceptable y ego-distónico, sin embargo en los pacientes con neurosis, el examen de la realidad se encuentra casi intacto y la conducta no infringe activamente las reglas sociales grupales. En el glosario mencionado, el proceso neurotico se define como un proceso etiológico específico donde los conflictos inconscientes provocan una percepción inconsciente de peligro anticipado, conduciendo al uso de mecanismos de defense que resultan en síntomas y/o alteración de la personalidad (Torres, 2003)

\section{¿Qué es la psicosis?}

La psicosis, son aquellos trastornos de la mente caracterizados por una cierta pérdida de contacto con la realidad. Cuando una persona sufre este tipo de trastorno se dice que ha tenido un "episodio". La psicosis afecta principalmente a los jóvenes adultos y es bastante común. Cerca de tres de cada cien jóvenes sufrirán un episodio psicótico, lo cual significa que, entre este sector de la población, la psicosis es más común que la diabetes. La mayor parte de los afectados consigue una plena recuperación del trastorno. La psicosis puede afectar a cualquiera, y como toda enfermedad, es susceptible de tratamiento. La persona afectada por esta alteración de su mente, puede presentar pensamientos confusos, creencias falsas, alucinaciones, cambios afectivos y de percepción, cambios de conducta. ${ }^{9}$

Torres (2003) menciona que Fish (1967) en su Clinical Psychopathology, define a la psicosis como una distorsión total de la personalidad con falta de discernimiento, construcción de ambiente ficticio (a causa de experiencias subjetivas), trastorno extremo de los instintos básicos (incluido el de supervivencia) e incapacidad para una adaptación social razonable.
Por otro lado, Van Praag (1998) alude que, "en lugar de hablar de esquizofrenias, trastornos de pánico, o de depresión mayor, podríamos estudiar los trastornos en la percepción, en el proceso de la información, en la regulación del humor, de la ansiedad o de los trastornos en el control de impulsos por señalar algunas áreas (Torres, 2003, p. 30).

Retomo aquí a Carl Jung (2015, pp. 83-87) médico psiquiatra, quien sostiene, que hoy día, nadie duda de la base psicogenética de la neurosis. Piscogénesis significa que la causa esencial de una neurosis o la condición bajo la cual aparece es de naturaleza psíquica, como por ejemplo, un choque emocional, un conflicto desmoralizador, un tipo de adaptación psíquica equivocada, una ilusión fatal, entre otras. También expresa "tan clara e indudable como parece ser hoy día la motivación psíquica de la neurosis, así tan oscura y dudosa es la cuestión de la psicogénesis en el caso de las enfermedades mentales."

En relación con las esquizofrenias, Jung (2015, p. 84) sostiene que estas tienen una "psicología, es decir, una causalidad y finalidad psíquicas, al igual que en la vida mental normal, pero con una diferencia importante: mientras que en la persona sana el yo es el sujeto de su experiencia, en el esquizofrénico el yo es solo uno de los sujetos que experimenta. Es decir, en la esquizofrenia el sujeto normal se ha desdoblado en una pluralidad de sujetos o en una pluralidad de complejos autónomos, como denomina la expresión técnica. El caso más simple de la esquizofrenia, es decir del desdoblamiento de la personalidad, es la llamada paranoia, la manía de persecución clásica del persécuteur persécuté.

Por otro lado, volviendo al caso de la paranoia, Jung expresa, que debemos preguntarnos: desde el punto de vista psicológico, ¿̇tiene algún sentido que la idea de persecución se haya apoderado de él y haya usurpado una parte de su personalidad?, ¿se trata, en otras palabras, 
simplemente de un producto de un trastorno orgánico del cerebro, que alguna vez tuvo lugar? Si fuese así, la idea fija no sería psicológica; le faltaría la causalidad y la finalidad psicológicas ya no sería psicogénica. Pero si se comprobara que la idea patológica no apareció en un momento cualquiera, que apareció en un momento psicológico particular, entonces tendríamos que hablar de psicogénesis, aun si se supusiera que en el cerebro siempre hubo una predisposición que en parte es responsable de la enfermedad.

Otro punto importante que refiere Carl Jung, sobre la esquizofrenia es la siguiente:

La psicogénesis de la esquizofrenia también explica qué ciertos casos más leves -que ciertamente no llegan a los manicomios, sino que aparecen en los consultorios del neurólogo -pueden ser curados por medios psicoterapéuticos. Sin embargo, con respecto a la posibilidad de una cura no conviene ser demasiado optimista. Estos casos son raros. La misma naturaleza de la enfermedad, que comprende la desintegración de la personalidad, excluye la posibilidad de la influencia psíquica, que es el agente esencial de la terapia. La esquizofrenia comparte esta peculiaridad con la neurosis obsesiva, su pariente más cercano en el área de la neurosis.

En cuanto a la psicogénesis de la esquizofrenia, Carl Jung $(2015$, p. 102) afirma que han llegado a la conclusión de que el problema mismo es muy complicado, sin embargo, se da la tarea de aclarar que el término psicogénesis significa dos cosas diferentes: Un origen exclusivamente psicológico; y una serie de condiciones psicológicas. Al respecto Jung, alude "hemos tratado el segundo punto, pero no hemos tocado todavía el primero." Este enfoca la psicogénesis desde el punto de visa de una causa efficiens. La pregunta es: la única y absoluta causa de la esquizofrenia, ¿'es psicológica o no? Esta pregunta, alude Jung, "como ustedes saben en toda el área de la medicina es más que embarazosa". Solo en muy pocos casos puede ser contestada en forma positiva:
“[...] es prácticamente imposible demostrar, aunque sea en forma aproximada, que la esquizofrenia es, en primer lugar, una enfermedad orgánica. Es igualmente imposible probar su origen exclusivamente psicológico. Podemos tener fuertes sospechas sobre la naturaleza orgánica de los síntomas primarios, pero no podemos ignorar el hecho probado de que existen muchos casos que se han desarrollado a partir de un shock emocional, una decepción, una situación difícil, un giro, un destino. Y que, además, muchos contratiempos, así como mejorías, se deben a condiciones psicológicas. ¿Qué podemos decir de un caso como el siguiente?, un joven estudiante experimenta una decepción en un asunto amoroso. Sufre un ataque catatónico, del que se recupera después de algunos meses. Luego termina sus estudios y tiene mucho éxito en su profesión. Después de muchos años vuelve a Zúrich, donde había vivido su aventura amorosa. De inmediato sufre un nuevo y muy similar ataque. Dice que cree haber visto a la chica en algún lado. Se recupera y durante varios años evita visitar Zúrich. Luego vuelve y pocos días después está de vuelta en la clínica con un ataque catatónico, de nuevo bajo la impresión de haber visto a la chica, que entretanto se había casado y tenía hijos".

Mi maestro, Eugen Bleuler, solía decir que una causa psicológica solo puede producir los síntomas de una enfermedad, pero no la enfermedad misma. [...] Sin lugar a dudas pasará mucho tiempo antes de que la fisiología y la patología del cerebro, por un lado, y la psicología del inconsciente, por el otro, puedan estrecharse la mano. Hasta entonces deben ir por caminos separados. Sin embargo, la psiquiatría, cuya preocupación es el hombre todo, está obligada por su tarea de comprender y tratar al enfermo, a tener en cuenta ambos lados, sin considerar el abismo que existe entre los dos aspectos del fenómeno psíquico. Aunque nuestros conocimientos actuales no nos permiten todavía descubrir los puentes que conectan la naturaleza tangible y visible del cerebro con la aparente sustancialidad de las formas psíquicas, 
existe la seguridad infalible de su presencia. Que esta seguridad impida a los investigadores cometer el error de desatender un lado a favor del otro o desear reemplazar el uno por el otro. La naturaleza no existiría sin sustancia y tampoco existiría si no se refleja en la psiquis.

\section{Las emociones y los sentimientos}

Damasio (2010, pp. 174-175) manifiesta, que cuando hablamos de las emociones propiamente dichas como el miedo, la ira, la tristeza, la alegría, o el disgusto, son componentes constitutivos de cada emoción e intervienen de manera independiente en la regulación de la vida. Las emociones son programas complejos de acciones, en amplia medida automáticos, confeccionados por la evolución. Las acciones se complementan con un programa cognitivo que incluye ideas y modos de cognición, pero el mundo de las emociones es en amplia medida un mundo de acciones que se llevan a cabo en nuestros cuerpos, desde las expresiones faciales y las posturas, hasta los cambios en las vísceras, el medio interno. Por otro lado, las sensaciones que sentimos de las emociones, son percepciones mixtas de lo que sucede en nuestro cuerpo y mente, cuando manifiestan emociones.

Así en lo relativo al cuerpo, las sensaciones sentidas son imágenes de acciones más que acciones, y el mundo de los sentimientos está hecho de percepciones consumadas en mapas cerebrales. Las percepciones que Ilamamos sentimientos de emociones constan de un componente especial que corresponde a esos sentimientos que se basan en la relación única entre el cuerpo y cerebro, que la interocepción ${ }^{10}$ privilegia. También

10 Percepción del estado interno del organismo, aportando información sobre el funcionamiento o disfunción de las vísceras y órganos internos. Se trata de un sentido que nos ayuda a mantener la homeostasis o equilibrio corporal. Con frecuencia poco valorada, la interocepción es algo vital para la supervivencia, gracias a ella podemos percibir que estamos heridos, que algo no va bien con nuestro organismo que necesitamos beber agua o comer, o que estamos alude Damasio (2010, p. 173) que hay otros aspectos del cuerpo que están, sin duda, representados en los sentimientos emocionales, pero a menudo la interocepción domina el proceso y es responsable de aquello que llamamos el aspecto "sentido" de estas percepciones. En consecuencia, las emociones son percepciones que se acompañan de ideas y modos de pensamiento, los sentimientos emocionales, son principalmente percepciones de lo que nuestro cuerpo hace mientras se manifiesta la emoción, junto con percepciones del estado de nuestra mente durante ese mismo periodo de tiempo.

\section{Modelos curativos desde la psiquiatría y psicoterapia}

Carl Jung, con una fructífera y larga trayectoria como psiquiatra y psicoterapeuta, desarrolló técnicas diferentes e improvisadas para el restablecimiento y sanación de los pacientes. Cuando las palabras fracasaban, apelaba al arte, al baile, a la actuación, a cualquier cosa que derribase las murallas del silencio o de la verbosidad que levantase al paciente. Para Jung, el inconsciente es por encima de todo creativo, y su creatividad se centra en conservar al individuo en el camino hacia el todo.

Utilizó métodos no verbales para curar la psique en proceso de desintegración. Este tipo de métodos fueron practicados en el mundo no occidental millares de años, antes de que surgiera la psicoterapia. Igualmente, expone muchos casos de pacientes diagnosticados con alteraciones psicóticas, recuperadas totalmente, desde el inconsciente de la persona. Sin embargo, como se ha expuesto anteriormente, Jung fue profundamente minucioso y cuidadoso al diagnosticar todo tipo de alteración psicoemocional, pues como bien lo ha sugerido e informado en sus múltiples libros como conferencias, no

sexualmente excitados. Si bien a veces es separada de la interocepción, la percepción del dolor o nocicepción, también estaría incluida dentro de la capacidad de detector los cambios en el equilibrio corporal (psicologiaymente.com). 
todos los casos de esquizofrenia son orgánicos, los cuales son muy pocos, pero hay muchos más casos de carácter psicológico, reconociendo que los conocimientos actuales no les permiten descubrir los puentes que conectan la naturaleza tangible y visible del cerebro con la aparente insustancialidad de las formas psíquicas, pero si existe la objetividad infalible de su presencia.

Sechehaye (2017, p. 127), psicoterapeuta suiza, quién a través del método llamado La realización simbólica, expone un nuevo camino en la sanación y curación total de una adolescente de 14 años diagnosticada de esquizofrenia, quién más tarde terminó de manera brillante sus estudios, estableciéndose con una amiga, también bióloga, en una ciudad cercana de Ginebra, donde ambas se dedican con afán a las mismas investigaciones. Sechehaye, después de una larga y ardua labor psicoterapeuta empezó a comprender el mundo simbólico de las expresiones verbales de su paciente, hasta que llegó al mundo intrauterino de la paciente, y así pudo empezar a desarrollarse en armonía esa bebé hasta su recuperación total. La psicoterapeuta suiza, expresa: "Renée ha conservado para mí un profundo cariño y me visita siempre que las circunstancias lo permiten" (2017, p.127).

Neil T. Anderson (2013, pp. 177-181) ministro de la Iglesia Cristiana de Tennessee, atendió a Judy una joven de 26 años de edad, tenía diploma de profesora y había sido diagnosticada de esquizofrenia. Durante cinco años, tres veces había sido ingresada a un hospital psiquiátrico sin haber logrado recuperación alguna. Después de varias reuniones en el ministerio cristiano, Judy comenzó a enfrentar sus sentimientos no resueltos hacia su padre y resolvió el problema del perdón que era el quid de su situación emocional. "A los pocos meses, esta joven que había sido diagnosticada de esquizofrenia por los médicos psiquiatras y le habían diagnosticado como incurable, hizo su significativo progreso y se ocupó en el ministerio con nuestros niños en la iglesia" (Anderson, 2013).

\section{Discurso narrativo de la sanación espiritual de un adolescente, caso de este estudio}

En el caso del adolescente que recibió sanación pastoral de una congregación cristiana, primero enfrentó episodio de bulling escolar durante su primer año de preparatoria, principalmente por parte de algunos maestros y la indiferencia del departamento psicológico de la referida institución escolar. Posteriormente, fue trasladado a estudiar en otra institución escolar. Además de estos acontecimientos se enfrenta al divorcio de sus padres, como también los tres adolescentes que padecieron episodios de depresión y ansiedad, los tres provenientes de familias cuyos padres estaban divorciados y tanto por la vía materna como paterna formaron nuevas familias.

El caso a describir en este apartado, corresponde al adolescente que cuenta con tres informes médicos psiquiátricos, por escrito (se les nombrará en orden con letras mayúsculas $A, B$, y C). En el primer informe escrito, el diagnóstico fue fobia social o ansiedad -estrés social con posible tipo de depresión (B, enero 2015). El segundo informe médico ( $C$, febrero 2017), el diagnóstico fue "trastorno depresivo recurrente, episodio actual grave. Trastorno de ansiedad generalizada", manifestando "generar un ambiente familiar favorable para el desarrollo del paciente", para lo cual recomienda tratamiento farmacológico de baja dosis (fármaco no controlado) de toma diaria por las noches. Aun teniendo el diagnóstico el médico " $\mathrm{C}$ ", en la práctica manifiesta que el paciente sufre de "esquizofrenia", lo cual no coincide con el informe que el mismo doctor $\mathrm{C}$, redacta y firma el mencionado informe. Previamente a estos dos diagnósticos, "una psicóloga y un psiquiatra" (A) (denominaremos A, diciembre 2014) que trabajan como equipo disciplinario, diagnosticaron "esquizofrenia del tipo paranoide". Esto en una primera cita, siendo que la psicóloga no atendió al paciente, debido a que el adolescente le manifestó personalmente que no deseaba pasar consulta con la referida profesional; sin embargo esta psicóloga fue quien 
derivó al psiquiatra en mención (A), inclusive ambos profesionales recomendaron internar al adolescente un largo tiempo en el hospital. Este proceder rompe con el principio médico primon non nocere. Se debe manifestar que a pesar de la vulnerabilidad emocional de aquel cuerpecito adolescente junto a la familia materna, fehacientemente se opusieron a dicha sugerencia apresura$\mathrm{da}$, aunque la figura paterna estaba de acuerdo en todo lo que manifestaban los profesionales " $A$ ".

Patricia Muñoz, en su libro Los hijos del divorcio (2013, pp. 14-15) proclama "sea cual fuere la naturaleza de su divorcio, no ponga a los hijos en medio de sus conflictos, y recuerde que sus niños deben mantenerse fuera de sus pleitos y no tomar partido", asimismo Muñoz, hace énfasis, al expresar "nunca obligue a sus hijos a escuchar sus problemas, como tampoco los comprometa a escoger un bando, icuidado! mientras más discuta, corre más riesgos de un constante desequilibrio emocional, creando tensión en el hogar a la vez que disminuye su autoridad, porque no debe olvidar: lo mejor para los niños es un buen matrimonio y lo peor, uno malo. Asimismo, Muñoz (2013) refiere que es natural que de manera inmediata y después del divorcio se sienta desesperado por las consecuencias $y$, por consiguiente, hay quienes tratan de mantener vivo el vínculo. Aunque en ocasiones no faltan quienes dedican su tiempo a "castigar" a su ex -compañero(a), y tratan de no desperdiciar una sola oportunidad para continuar con los pleitos durante y después de los trámites legales, con el propósito de perpetuar hostilidad, la cual reinó durante el tiempo que estuvieron juntos. Recomienda esta autora "es importante aclarar que uno de los resultados positivos de vencer el tormento del pasado es la libertad que nos da para luchar por la felicidad futura."

La angustiante preocupación de la familia materna, llevó a buscar a médicos especialistas y con reconocida experiencia en clínicos y de contexto. El doctor $B$, con doctorado en medicina psiquiátrica y estancias de in- vestigación en diferentes universidades fuera del país, principalmente en la UNAM y Harvard University, descartó todo problema patológico de esquizofrenia. La familia materna estuvo presente en este diagnóstico y con una dinámica familiar entre paciente, médico y familia. Así la historia de los casos de estudio, principalmente de este cuerpo adolescente que, a pesar de su situación emocional alterada, participó y reaccionó para no aceptar una enfermedad patológica, la cual el jovencito manifestó "manipulan y mienten a mi mamá, es para hacerla sufrir..."

Por recomendación de una gran amiga de la familia materna, quien es cristiana en su formación religiosa, organizó una reunión con la pastora de su congregación y llevaron a cabo el proceso de sanación espiritual del joven, quien estaba en una fase de profunda crisis y con síntomas de paranoia. No toda paranoia es una esquizofrenia.

La pastora con su profunda fe espiritual divina, decretó la negación de toda enfermedad esquizofrénica, citando textos bíblicos, pronunciando la enseñanza de Jesucristo, sanador de "los malos espíritus que se apoderan de las personas". Así inició, la sanación en un parque de verde pasto, en un atardecer de verano.

Recuerdo que mientras la pastora oraba en muchas lenguas, el adolescente en crisis y en su dolorosa confusión, no aceptaba sanación y expresaba "no deseo que me hagan daño...", sin embargo, estaba allí. La pastora seguía orando por la salud del adolescente, y de manera inexplicable, el adolescente empezó a repetir todas las oraciones que declamaba la pastora. Estas fueron las frases que recitó, "creo en Cristo, creo en Cristo, creo en Cristo sanador y levantaba sus manos hacia arriba: ¿el cielo?...". Sentado sobre el verde pasto, frente a la pastora, la familia materna alrededor, la amiga cristiana de la familia y su hija con música de Dios, oraban y oraban. Y quien escribe estas líneas, como observadora participante. 
La pastora conforme oraba, empezó a entrar al vientre de la madre, regresando al adolescente a su tiempo de fecundación, lo regresó a su mundo uterino maternal, y desde allí empezó hablarle de su concepción, de la añoranza y el amor de sus padres para recibirlo en su nacimiento. Le hablaba al pequeño bebé en el vientre que era bien amado, que sus padres lo amaban, y que perdonara todo dolor causado involuntariamente, y siguió orando desde la fecundación hasta su nacimiento, en este mundo real objetivo, hasta continuar en el proceso de su desarrollo desde infante, niño y adolescente de aquel cuerpito angustiado.

La pastora seguía agradeciendo y decretando sanación total, en nombre de nuestro Señor Jesucristo. Cuando la pastora terminaba de orar, pidió al adolescente abrir lentamente sus ojitos, le rodaban sus lágrimas como pequeñas semillas, las cuales semejaban a los de su mamá quien también estaba presente. iSe levantó y expresó, imami, mami y la abrazó y se abrazaron llorando profundamente y hablando de perdón por el divorcio de sus padres! Luego el adolescente abrazó a la pastora y a la amiga cristiana junto a su hija, expresándoles gracias por orar, y se fue saltando por la acera. Un año sin hablar, se mantuvo en silencio, callado, serio, ni siquiera tenía afecto para abrazar o permitir un abrazo. Rara vez, daba un abrazo o se dejaba abrazar iQué experiencia tan dolorosa!, qué hacemos los padres cuando decidimos una separación, qué hacemos, solo egoístamente pensamos en nosotros, pero de manera involuntaria y con desconocimiento total, pensamos en que afectará psicoemocionalmente a nuestros hijos.

Esta experiencia y vivencia ante estos eventos, ha calado profundamente mi espíritu en este caminar del cuerpo y la psique con sus pensamientos, emociones, sensibilidades y la intuición, temas de interés que ya estaban latentes desde mi vida universitaria como estudiante.
La unidad familiar no como matrimonio, para integrarse como padres en resolver el estado emocional de los adolescentes, ha brindado parámetros de una adecuada recuperación emocional, no obstante, la psicoterapia continuará, tanto para los adolescentes como para los padres, porque es la parte medular del problema emocional, igualmente el tratamiento farmacológico ayudó en parte a estabilizar la ansiedad de ambos adolescentes jóvenes. Sin embargo, la estabilidad familiar ha sido fundamental en este proceso de sanación.

\section{Reflexiones y consideraciones}

Vivir para comprender la vida emocional de nosotros, seres humanos, enseña hondamente a reconocer que hay una parte de nuestra existencia, tan sensible y vulnerable como la psique humana, y que cuando esta enfrenta situaciones estresantes en distintos contextos, pueden desencadenar inadecuados procesos de alteraciones en el pensamiento, y estos generar emociones distorsionadas en la percepción de la realidad. En este sentido, el ser humano como persona necesita de una gran comprensión en los diferentes contextos en el que desarrolla sus cotidianidades, sobre todo con nuestros hijos que procreamos con tanta felicidad.

Esta dolorosa experiencia y vivencia, me transporta al cuerpo fenoménico según Merleau -Ponty (citado en Aisenson, 1981, p. 75) que ilustra cómo el cuerpo en su integridad, tanto en la calidad de ente biológico como en su dimensión vivencial, sentido como cuerpo propio, participa en la organización de la vida personal. Dicha concepción nace en Merleau -Ponty, del convencimiento de que la conciencia del hombre es fundamentalmente conciencia comprometida, porque siempre, de manera ineludible, su vida transcurre en el mundo, trabada con las cosas, y en su conducta se funden en íntima compenetración, tanto el plano subjetivo y el objetivo. 
Esta lectura experiencial y vivencial con cuatro adolescentes que han vivido momentos difíciles con la separación familiar, en relación a la separación de sus padres, recapitula lo que Patricia Muñoz (2003), escribe acerca de los hijos del divorcio:

En una etapa tan decisiva como es la adolescencia, es de especial importancia la crisis de la "identidad", donde el joven debe incorporar a su yo una variedad de cambios físicos e irse definiendo en cuanto a los roles que va a jugar en su vida adulta. El adolescente lucha por una independencia de los progenitores, pero a la vez no quisiera dejar de ser niño y seguir siendo protegido por ellos. El impacto de la desilusión matrimonial es reflejado por la depresión y sentimiento de culpa, así como por crisis situacionales. Muchos llegan a necesitar ayuda terapéutica, otros manifiestan conductas impulsivas... así, se observan las cadenas de matrimonios forzados y tempranos que acaban en la separación.

Finalmente se puede reflexionar y concluir que la familia constituye el eje motor de la estabilidad bio-psico-afectiva en las emociones y sentimientos de los hijos, principalmente en el proceso de su madurez, de la trascendencia de niño hacia adolescente, joven y adulto.

Los médicos psiquiatras, psicólogos y psicoterapeutas durante el proceso de terapias deberían trabajar aunados a la familia, con la finalidad de que esta, obtenga las herramientas teóricas necesarias para trabajar en el proceso de salud de los adolescentes en crisis.

Que toda terapia y sesiones a desarrollar para el tratamiento psicoterapéutico, sea elaborado por escrito y entregado a los padres tutores o familiares encargados de seguir el control de la salud emocional.

Trabajar las emociones y sentimientos del ser humano, demanda un alto nivel de comprensión humana hacia el otro, de profundo conocimiento al problema, y de realizar no solo una forma de terapia, pues se cae en un "univocismo" absoluto, siendo tardada la recuperación de la salud o bien se convierte en una terapia no adecuada para ese ser humano con una psicología humana que requiere de una atención multidisciplinaria con sentido bioético.

Si Hipócrates había expresado "que tu alimento sea la medicina de tu cuerpo", se puede afirmar que para todos los profesionales de la medicina, en especial para la psiquiatría y psicología que se discute en este tema, la misión será: "que tu bioética sea alimento profesional y humano para la recuperación de la salud mental en las personas que padecen algún episodio de alteración psicoemocional" (cursivas de R. Yépez, febrero 18, 2019).

En cuanto al diagnóstico de los profesionales " $A$ " mencionados en este corto discurso narrativo, aunque se desconoce cuál fue el objetivo de atemorizar al adolescente y la familia materna, pero siendo profesionales y con ética, estimo que su conocimiento encaja, en lo que Carl Jung (2015, pp. 66-67) manifiesta, que el desarrollo de las ciencias naturales trajo consigo un criterio general del mundo: el materialismo científico que se basa desde el punto de vista psicológico, en una sobrevaluación excesiva de la causalidad física. El materialismo científico automáticamente se niega a reconocer alguna conexión causal que no sea física. El dogma materialista, como lo formula la psiquiatría, dice: Enfermedades mentales son enfermedades del cerebro. Así, se desconoce que "el paciente es un ser humano con una psicología humana, debido a esta desvalorización característica del criterio psicológico, no se investigan las causas que provocaron la enfermedad", y esto sucedió en el joven adolescente que accedió a la sanación cristiana y ha empezado a acudir a los servicios pastorales.

Este trabajo constituye el inicio de un amplio campo que escudriñar, el cual se continuará investigando. 


\section{Agradecimientos}

Deseo expresar mi especial y profundo agradecimiento a la Dra. Josefina Ramírez V., por su invitación para participar en el III Encuentro Latinoamericano de Investigadores sobre Cuerpos y Corporalidades en las Culturas. Escrituras, Lecturas e Interpretaciones de los Cuerpos y Corporalidades entre la Ciencia y la $\mathrm{Fe}$, realizado en noviembre 2018 en las instalaciones del Palacio de Medicina, México. Principalmente mi participación fue en el Grupo de trabajo 2 "Cuerpos, corporalidades en los procesos -salud, enfermedad-atención" bajo la coordinación de la Dra. Ramírez. Del mismo modo, deseo agradecer ampliamente a los doctores en psiquiatría, $\mathrm{R}$. Pascual Salin y Dante Cabos Yépez, quienes siempre estuvieron atentos y con entusiasmo a escuchar mis dudas y brindarme sus conocimientos sobre las alteraciones psicoemocionales, con especial referencia a la psicosis. Reconozco en ambos, su alta calidad y bioética para trasmitir conocimiento y asesoramiento a los padres de los dos adolescentes, y el permitirme participar como observadora participante.

\section{Referencias}

Aisenson K., A. (1981). Cuerpo y persona. Filosofía y psicología del cuerpo vivido. México: Fondo de Cultura Económica.

Aguilar, M. A., y Soto Villagrán, P. (2013). Cuerpos, espacios y emociones. Aproximaciones desde las ciencias sociales (Coords). México: Editorial Porrúa.

Anderson, N. T. (2013). Victoria sobre la oscuridad. Reconoce el poder de tu identidad en Cristo. Colombia: Serie Favoritos.

Boixareu, R. M. (Coord). (2008). De la antropología filosófica a la antropología de la salud. España: Editorial Herder.

Campos-Navarro, R. (2016). Antropología médica e interculturalidad. México: McGraw Hill.

Casalprim, R. (2013). El cuerpo y las psicosis. Norte de salud mental, $X I(47)$, p. 107. España.

Citro, S. (2011). Cuerpos plurales. Antropología de y desde los cuerpos. Argentina: Editorial Biblos.

Damasio, A. (2010). Y el cerebro creó al hombre. ¿Cómo pudo el cerebro generar emociones, sentimientos, ideas y el yo? España: Ediciones Destino.

Guinsberg Blanck, E. (2010). "La salud mental en nuestros tiempos", en La medicina social en México I, Experiencia, subjetividad y salud. Florencia Peña, Saint Martin y Beatriz León Parra (Coords.) México: Ediciones Gráfico Eón S.A.

Espinoza Ramírez, L. O. (2010). La posmodernidad, lo sublime y un ojo cortado. Nota a propósito de la estética de Jean -François Lyotard. Poliantea, 6(11), pp. 11-21.

Jung, C. (2008). El hombre y sus símbolos. España: Editorial Paidós.

(2015). El contenido de la psicosis. Psicogénesis de las en fermedades mentales/2. España: Editorial Paidós.

(2004). "Sobre los arquetipos del inconsciente colectivo." En Hombre y sentido. C.G. Jung, W.F. Otto, H. Zimmwe, P. Hadot y J. Layard. Presentación de Ortíz -Osés. España: Editorial Anthropos.

Lyotard, J.F. (2004). La condición posmoderna. Madrid: Cátedra.

Martínez Hernández, Á. (2011). Antropología médica. Teorías sobre la cultura, el poder y la enfermedad. España: Editorial Anthropos.

Morales Sáez, N. (2016). “Proceso de salud-enfermedad mental -atención." En Antropología médica e interculturalidad. Roberto Campos Navarro, pp. 286 -295. México: Editorial McGraw Hill. 
Muñoz, P. (2013). Los hijos del divorcio. México: Editorial Libro SA de CV.

Ramírez Velázquez, J. (2010). “El desarrollo de una antropología física crítica y la generación de antropólogos físicos situados". Memorias del primer congreso nacional de antropología social y etnología de México. México: Rectoría de la UNAM.

Rosemberg Seifer, F. (2008). "La violencia como enfermedad: una mirada desde la etnopsiquiatria". En Cultura y desorden mental. Miradas desde la etnopsiquiatría y el etnopsicoanálisis. Francisco del a Peña M. (Coord.). México: Enah-Inah, Conaculta.

Sierra, J. C. (2006). Factores asociados a la ansiedad y fobia social. Revista Mal-Estar y Subjetividades/Fortaleza, VI(2), pp. 472-517.
State Government Victoria. Department of Human Services. www. eppic.org.au

Torralba, F. (2008). "El Ser Humano, una realidad personal". En De la antropología filosófica a la antropología de la salud. (pp. 33-44). España: Editorial Herder.

Turner, V. (1994). Los avances recientes en la Teoría del cuerpo. Revista Reis, (68), pp. 11-39. España.

Winski, N. (1973). Entendiendo a Jung. México: Editorial Diana. 